\title{
O conhecimento do belo em Schopenhauer
}

\author{
Guilherme Marconi Germer \\ Mestre em Filosofia pela Unicamp - Bolsista CNPq
}

RESUMO: Apresentaremos sumariamente o esclarecimento metafísico de Schopenhauer do belo - o qual, para ele, "recebeu pela primeira vez sua explanação apropriada durante todo o... terceiro livro" de Die Welt als Wille und Vorstellung. Em linhas gerais, Schopenhauer aclara que o conhecimento do belo se eleva sobre o conhecimento ordinário e o científico: pois esse tem, pelo lado objetivo, os fenômenos relativos e fugazes do princípio de razão, e pelo subjetivo, o sujeito cognoscente subordinado à Vontade; enquanto que o conhecimento o do belo consiste, pelo lado objetivo, nas Idéias eternas e arquetípicas de Platão, a "objetivação mais adequada possível da Vontade", e pelo subjetivo, o "puro e atemporal sujeito do conhecimento destituído de Vontade e sofrimento". Contudo, o filósofo adverte que o belo ainda é um "sonho passageiro", pois só liberta momentaneamente da Vontade, e não definitivamente, como o ascetismo.

PALAVRAS CHAVE: Pessimismo, Soteriologia, Ideia de Platão.

ABSTRACT: We will briefly present Schopenhauer's metaphysical clarification of the beautiful which, for him, "first received its proper explanation along the whole. .. third book" of Die Welt als Wille und Vorstellung. Generally speaking, Schopenhauer clarifies that the knowledge of the beautiful rises above ordinary and scientific knowledge: for the latter has, on the objective side, the relative and fleeting phenomena of the principle of reason, and on the subjective side, the knowing subject subordinate to the Will (needy, dissatisfaction and tedium), whereas the beautiful has on the objective side, the eternal and archetypal ideas of Plato, the "best possible objectification of the Will," and on the subjective side, "the pure and timeless subject of knowledge devoid of will and suffering". However, the beautiful is still a "passing dream" to the philosopher, because it only briefly liberates from the will, and not definitely, as asceticism does.

KEY WORDS: Pessimism, Soteriology, Plato's Ideas.

Schopenhauer se apresenta como o primeiro filósofo a estabelecer a correlação do sujeito e do objeto como a forma primordial do conhecimento. Conforme o seu pensamento, sujeito e objeto são inseparáveis, inteiramente correlatos, existentes somente por e para o outro; e uma conseqüência ou prova disso é que nós podemos conhecer as "formas essenciais e universais de todo objeto... partindo-se do sujeito, sem o conhecimento do objeto, isto é, na linguagem de Kant, elas residem a priori em nossa consciência"3.

Entretanto, Schopenhauer assevera que Kant não estabelece corretamente o conteúdo desta "fronteira comum" a priori do sujeito e objeto, pois em primeiro lugar, ele não reconhece a forma "primeira, principal e mais universal" da representação, a saber, a de ser objeto para um sujeito (das Objekt-für-ein-Subjekt-Sein) ${ }^{4}$; e em segundo lugar, ele também não esclarece devidamente uma forma "secundária e subordinada" a esta primeira,

\footnotetext{
${ }^{1}$ WWV I I, p. 252. MVR I, p. 459.

${ }^{2}$ Ibdem..

${ }^{3}$ WWV I, p. 34. MVR I, p. 46.

${ }^{4}$ Idem, p. 252. Idem, p. 242
} 
cuja expressão geral é o princípio de razão suficiente (Satz vom zureichenden Grunde). Conforme o filósofo de Frankfurt, tanto o conhecimento ordinário quanto o científico limitam-se a ambas as formas objetivas. No entanto, o conhecimento do belo é livre de, ou melhor, é anterior à segunda forma, a saber, o princípio de razão suficiente, e atém-se tão somente à primeira, vale dizer, o ser objeto para um sujeito. Nossa comunicação tem o objetivo de apresentar as linhas gerais da teoria schopenhaueriana do conhecimento do belo. Destarte, nós primeiro apresentaremos uma descrição geral da teoria do filósofo do conhecimento conforme o princípio de razão, e depois nos dirigiremos mais detalhadamente à sua concepção do belo propriamente dita:

Schopenhauer enuncia que o princípio de razão suficiente tem por fórmula geral a seguinte expressão: "Nada é sem uma razão pela que é" (Nichts ist ohne Grund, warum es sei und nicht vielmehr nicht sei) ${ }^{5}$. A partir desta expressão, o pensador entende que ele se ramifica em quatro raízes, por meio das quais rege de modo a priori as quatro seguintes classes de objetos: (1) os fenômenos materiais empíricos, (2) os conceitos, (3) as partes do espaço puro e do tempo puro e (4) os sentimentos internos. Destarte, o filósofo entende que todos os objetos destas quatro classes têm por forma a priori, em primeiro lugar, o ser objeto para um sujeito, e em segundo, o ter uma razão, causa ou fundamento a partir da qual exista. Constatemo-las, pois, uma a uma: de acordo com o pensador, toda e qualquer representação empírica, material e intuitiva deve ter uma causa desta mesma classe de representação, que lhe seja temporalmente anterior. Logo, é a lei da causalidade (Gesetz der Kausatität) a primeira raiz a priori do princípio de razão. Em segundo lugar, todo e qualquer conceito, para que expresse um conhecimento, deve originar-se seja de um fenômeno empírico material, seja de outro conceito, seja de uma das quatro leis do pensamento $^{6}$, ou seja, da forma a priori do conhecimento empírico (o espaço puro, o tempo puro ou a lei da causalidade,). Conforme o pensador, é a segunda raiz do princípio de razão suficiente que estabelece esta conexão, denominada por princípio de razão suficiente do conhecer. Em terceiro lugar, todas as partes do espaço puro e do tempo puro "estão entre si

\footnotetext{
${ }^{5} \mathrm{SG}$, p. 15.

${ }^{6}$ Schopenhauer ensina que as quatro leis do pensamento são as seguintes: o princípio de identidade ("um sujeito é igual à soma de seus predicados, ou a = a"), o princípio de contradição ("nenhum predicado pode ser afirmado e negado sobre um mesmo sujeito, ou $\mathrm{a}=-\mathrm{a}=\mathrm{o}$ ), o princípio do terceiro excluído ("de dois predicados opostos contraditoriamente, um deles deve convir a um sujeito", e o princípio de razão suficiente do conhecer ("a verdade é a relação de um juízo com algo fora dele, que é sua razão suficiente"). SG, p. 133.
} 
numa relação, de modo que cada uma delas está determinada e condicionada por outra"7. No espaço puro, essas relações chamam-se posição, e no tempo, sucessão. Quem as estabelece a priori é, pois, o princípio de razão suficiente do ser. E em quarto lugar, todos os fenômenos internos, subordinados tão somente ao tempo e denominados pelo vasto conceito de sentimento, também devem possuir uma causa, da mesma maneira como qualquer fenômeno externo o possui: neste caso, será a lei da causalidade que os regerá, agora, porém, vista "por dentro”, como lei da motivação (Gesetz der Motivation) - a quarta raiz do princípio de razão. Sendo assim, o filósofo conclui que o princípio de razão mantém-se o mesmo sobre estas quatro classes de objetos: (1) os fenômenos materiais empíricos, (2) os conceitos, (3) as partes do espaço puro e do tempo puro e (4) os sentimentos internos. Conformo o pensador, todas elas são subordinadas, por fim, à fórmula geral a priori do princípio de razão "nada é sem uma razão pela que é".

No entanto, Schopenhauer adverte que o conhecimento conforme este princípio é sempre relativo, a saber: relativo, por um lado, ao sujeito do conhecimento, e por outro, a outra representação, sua causa, razão ou fundamento. Assim, ele esclarece que este conhecimento se limita aos porquês, ondes, quandos e comos das representações - e por isto ele é adotado pela metodologia científica. Contudo, justamente o quê das coisas não é por ele penetrado. Ademais, o filósofo assevera que esse conhecimento sempre está conectado "por um caminho mais curto ou mais longo, ao corpo, por conseqüência à

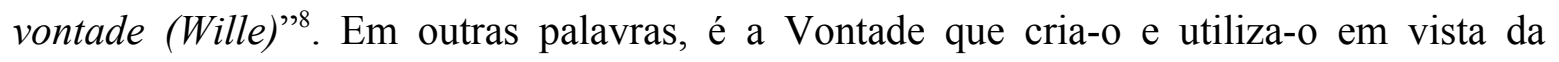
satisfação seus fins. Finalmente, o pensador alega que o tempo é o arquétipo desta experiência: pois o tempo é a condição das quatro classes de objetos anteriormente comentados. No entanto, como a natureza do tempo é "essencialmente desvanecedora", ele também é o grande responsável pelo caráter de não permanência, fugacidade, aparência e "ser e não ser" do conhecimento do princípio de razão. A respeito disso, o pensador escreve o seguinte:

Todo ser no tempo é também um não-ser (ein Nichtsein); pois o tempo é simplesmente aquilo no qual as mesmas coisas podem receber propriedades contrárias: assim, cada fenômeno no tempo também não é; pois o que separa seu início de seu fim é meramente tempo - algo essencialmente desvanecedor, sem permanência e relativo, aqui denominado duração. O tempo é a forma mais geral

${ }^{7}$ Idem, p. 158.

${ }^{8}$ WWV I, p. 254. MVR I, p. 24. 
de todos os objetos do conhecimento que permanece a serviço da Vontade e o arquétipo de todas as demais formas deste conhecer'.

Assim, em face do caráter relativo, fugaz, sem permanência e "ser e não ser" do conhecimento do princípio de razão, Schopenhauer admite ter que concordar com a atribuição de Platão de "Ser propriamente dito" (eigentliches Sein) tão somente às Idéias eternas (ewigen Ideen) ${ }^{10}$. Conseqüentemente, ele declara o seguinte:

Se nos fosse permitido seguir uma condição impossível (einer unmöglichen Voraussetzung) e conhecer não mais as coisas particulares, mudanças e multiplicidade, mas apenas as Idéias... o nosso mundo seria um Nunc Stans (um agora persistente, um presente permanente) ${ }^{11}$.

De acordo com Schopenhauer, as Idéias eternas são os arquétipos, os protótipos, os modelos das coisas. Elas são as formas atemporais, imutáveis, permanentes; são os caracteres, os "elementos puramente objetivo"; as "expressões completas da essência"; independentes de todas as relações - ou mesmo - "as somas (...) os pontos-raiz de todas as relações" ${ }^{12}$. Segundo seu pensamento, as Idéias são anteriores às formas do princípio de razão, mas ainda estão subordinadas à forma primeira e principal da representação, a saber, o ser objeto para um sujeito ${ }^{13}$. Para o filósofo, esta é a única determinação que as diferencia da coisa em si de Kant, a qual é livre de toda e qualquer forma de representação. A propósito, Schopenhauer acredita que a coisa em si kantiana se desvela no conhecimento que nós temos de nós mesmos, relacionado àquilo que há em nós toto genere distinto de representação, a saber, Vontade. Assim, como as Idéias de Platão estão entre a Vontade (a coisa em si) e os fenômenos do princípio de razão, elas são a "objetidade mais adequada possível da Vontade ou da coisa em si" (die möglichst adäquate Objetität des Willens oder Dinges an sich $)^{14}$. No entanto, eis a pergunta que surge: qual é o tipo de consideração que se endereça unicamente ao "essencial propriamente dito do mundo, alheio e independente de toda relação... não submetido a mudança alguma e, por conseguinte, conhecido com igual verdade por todo o tempo, numa palavra, às Idéias...? - Resposta: é a arte (Kunst), a

\footnotetext{
${ }^{9}$ Idem, p. 255 . Idem, p. 244.

${ }^{10}$ Idem, p. 261. Idem, p. 250

${ }^{11}$ Idem, p. 253. Idem, p. 242

${ }^{12}$ WWV II, p. 470.

${ }^{13}$ Idem, p. 252.

${ }^{14}$ WWV I, p. 253. MVR I, p. 242.
} 
obra do gênio"15. Em favor desta asserção, o filósofo recorda que somente a arte do gênio retira o objeto "da torrente fenomênica e o isola diante de si", e assim, permite a penetração em seu quê, o conhecimento de sua Idéia. Em poucas palavras, o pensador afirma que "a única origem da arte é a intuição da Idéia e seu único fím a comunicação deste conhecimento".

Contudo, não se pode desprezar o poder estético da bela natureza. Assim, Schopenhauer prefere relacionar o conhecimento da Idéia não exclusivamente à arte, mas, de modo geral, ao belo (o que engloba a arte humana e o belo natural). Em favor desta interpretação, o filósofo assinala o seguinte:

\footnotetext{
'Schön' (belo) está indubitavelmente conectado com 'to show' (revelar), em inglês, e conseqüentemente deve significar 'showy', 'what shows well' - o que revela bem, portanto aparece com clareza na percepção intuitiva; logo, a expressão clara das significativas Idéias de Platão ${ }^{16}$.
}

Assim, o alemão argumenta que quando predicamos algo de belo (schön), dizemos, em termos objetivos, que nele conhecemos "não a coisa particular, mas a Idéia". Todavia, como qualquer coisa particular é a objetivação de uma Idéia, a princípio, essa pode ser conhecida em qualquer coisa, logo, como conclui o filósofo: "Toda coisa é bela" "17. Para além desta alegre constatação, porém, o pensador adverte que há objetos que "facilitam a pura consideração objetiva, vem-lhe ao encontro, sim, como que compelem a isso": esses objetos são denominados, pois, de mais belos (schöner) ou muito belos (sehr schön) ${ }^{18}$. Segundo o pensador, isto ocorre a partir de dois fatores; por um lado:

Na medida em que uma coisa particular exprime de modo puro a Idéia de sua espécie mediante proporções bem claras, puramente determinadas e inteiramente significativa de suas partes, reunindo em si todas as exteriorizações da Idéia de sua espécie e manifestando-a com perfeição ${ }^{19}$.

E por outro lado, na medida em que a Idéia mesma exprimida no objeto "é de um grau superior de objetidade da Vontade e, por conseguinte, diz muito mais, é mais significativa" ${ }^{20}$. Assim, como a Idéia humana é o grau máximo de objetivação da Vontade -

\footnotetext{
${ }^{15}$ Idem, p. 265. Idem, p. 253.

${ }^{16}$ PP II, p. 500.

${ }^{17}$ WWV I, p. 298. MVR I, p. 283.

${ }^{18}$ Idem, p. 298. Idem, p. 283.

${ }^{19}$ Ibdem.

${ }^{20}$ Ibdem.
} 
o filósofo conclui o seguinte: $O$ ser humano é belo antes de qualquer outra coisa e a revelação (Offenbarung) de sua essência é o fim supremo da $\operatorname{arte}^{21}$.

Segundo Schopenhauer, a Idéia do ser humano, a correspondente a cada indivíduo humano, e mesmo as correspondentes às demais espécies de animais são:

A evidenciação (Offenbarungen) mais clara da Vontade, pois expõem a grande multiplicidade (Mannigfaltigkeit) de figuras, a riqueza e o significado profundo dos seus fenômenos, e nos ostentam da maneira mais perfeita a sua essência, seja em sua veemência, sobressalto, satisfação, ou em sua discórdia (nas exposições trágicas, em última instância), finalmente, até mesmo em sua viragem ou auto-supressão, que, em especial, é o tema da pintura cristã ${ }^{22}$.

Destarte, o pensador entende que as artes que facilitam a intuição dessas Idéias superiores, a saber, a poesia, a pintura histórica e a escultura de homens e de animais, são o ápice da beleza. Por outro, porém, o filósofo considera que na bela natureza, na pintura de paisagens e de naturezas-morta, na jardinagem, na hidráulica e na arquitetura - a saber, as artes que expressam as Idéias mais baixas - revelam-se "a bem-aventurança e tranqüilidade espiritual do conhecer puro, livre de todo querer, individualidade e do tormento ligado a ela" ${ }^{23}$, isto é, o lado subjetivo do belo, correlato necessário da pura objetidade (as Idéias). Comentemos sucintamente este segundo lado do belo:

Schopenhauer entende que a transição do conhecimento dos objetos do princípio de razão suficiente às Idéias eternas exige uma mudança análoga e correspondente no sujeito do conhecimento, o qual deve libertar-se da servidão à Vontade e tornar-se o atemporal $e$ puro sujeito do conhecimento destituido de Vontade (reines, willenloses... zeitloses Subjekt der Erkenntnis) ${ }^{24}$. No entanto, o pensador entende que a remoção da Vontade da consciência implica a extinção da "fonte de toda nossa tristeza e sofrimento" 25 . Assim, sua conclusão é que o belo sempre vem acompanhado por uma fruição desinteressada, baseada no "mero conhecimento, exclusivo e puro". Por fim, embora elogie esta apreciável via de salvação do sofrimento do mundo, o alemão adverte que o belo não deixa de ser um "sonho passageiro". Conforme seu pessimismo, são poucas as pessoas inclinadas à pura contemplação objetiva, e mesmo nelas, a beatitude estética dura pouco, e a Vontade retorna

\footnotetext{
${ }^{21}$ Ibdem.

${ }^{22}$ Idem, p. 301. Idem, p. 287.

${ }^{23}$ WWV I, p. 301. MVR I, p. 286.

${ }^{24}$ Idem, p. 257. Idem, p. 246.

${ }^{25}$ PP II, p. 490.
} 
rapidamente à consciência, com exigências que são ainda mais insuportáveis nesses espíritos. Destarte, o pensador afirma que o gênio é o ápice do sofrimento da Vontade; e sua dor revela que a única salvação definitiva do sofrimento ocorre não quando o intelecto cala a Vontade, no belo, mas quando a própria Vontade, a partir de seu autoconhecimento, cala-se a si própria: experiência esta que está na essência da santidade e do ascetismo.

Finalmente, há ainda uma arte que não foi aqui abordada, porquanto escapa da teoria schopenhaueriana de arte como repetição de uma Idéia: a música. Conforme o filósofo, a música não é a cópia ou a exposição de uma Idéia, mas objetiva toda a Vontade, de modo tão imediato, que expõe antes a própria Vontade, análoga e paralelamente a como as Idéias a expõem. Visualizemo-lo intuitivamente: a proposta do filósofo é que a Vontade se objetiva imediatamente, em graus mais baixos, por um lado, como o baixo contínuo musical, e por outro, como as Idéias da natureza inorgânica. Posteriormente, se objetiva imediatamente em graus progressivamente mais elevados, por um lado, como "o conjunto das vozes intermediárias que produzem a harmonia”, na música, e por outro, como a "seqüência integral das Idéias" que se eleva do reino vegetal ao animal. Por fim, a Vontade encontra o seu ápice tanto na melodia musical, como na Idéia ser humano - ambas as quais revelam a sua "história mais secreta e íntima".

Estas são, por fim, as linhas gerais do esclarecimento do belo de Arthur Schopenhauer. Esperamos haver suscitado com elas senão férteis intuições, ao menos o desejo de aprofundar-se nesta bela filosofia e o de saborear o mundo como beleza. Em nome destes três objetivos, pois, só podemos encerrar a nossa comunicação com o convite schopenhaueriano à música, com o qual ele conclui as suas preleções sobre a metafísica do belo: Que a audição e a execução musicais sejam sempre recomendadas a todos como participação nessa arte balsâmica ${ }^{26}$.

\section{Referências Bibliográficas}

SCHOPENHAUER, Arthur. Sämtliche Werke in fünf Bänden. Stuttgart/Frankfurt am Main: Suhrkamp, Erste Auflage1986.

SCHOPENHAUER, Arthur. O Mundo como Vontade e como Representação, tradução: Jair Barboza, São Paulo: Editora Unesp, 2005. 695p.

\footnotetext{
${ }^{26}$ SCHOPENHAUER, Arthur. Metafísica do Belo, tradução: Jair Barboza, São Paulo: Editora Unesp, 2003. P.
} 241. 
SCHOPENHAUER, Arthur. Metafísica do Belo, tradução: Jair Barboza, São Paulo: Editora Unesp, 2003. 249p.

Recebido: $24 / 10 / 10$

Received: $10 / 24 / 10$

Aprovado: 08/12/10

Approved: 12/08/10 